\title{
Midterm results of tricuspid annuloplasty with a homemade PTFE flexible ring
}

\author{
Salim Chibane*, Abdelmalek Bouzid, Mohamed Atbi, Halima Larbi, Ramdane Amar Ould Abderahmane \\ From World Society of Cardiothoracic Surgeons 25th Anniversary Congress, Edinburgh \\ Edinburgh, UK. 19-22 September 2015
}

\section{Background/Introduction}

Tricuspid regurgitation is a serious valvulopathy with a significant impact on long term survival. Several techniques have been described to address it, including suture techniques and ring techniques. All have the same purposes of favoring leaflet cooptation, reducing the size of the tricuspid annulus and stabilize the reparation to preclude further re expansion and dilatation of the annulus.

\section{Aims/Objectives}

The purpose of this study is to evaluate the outcome of tricuspid annuloplasty with a PTFE linear strip.

\section{Method}

From February 2009 to May 2013, seventy-two patients underwent tricuspid annuloplasty for functional tricuspid regurgitation (TR). In 32 patients, tricuspid annuloplasty was done with a linear strip of PTFE. All patients had a left valvulopathy associated. The mean age was 42.7 years and $15.6 \%$ were reoperations. Right heart failure was present in $19 \%$ of patients on admission and $56 \%$ had atrial fibrillation. Ten patients $(31.2 \%)$ were symptomatic (NYHA class 3 and 4) and 22 patients (69\%) had significant tricuspid regurgitation (grade 3-4).

\section{Results}

The mean follow-up was 18 months (min 4 months, max 53 months). Early and late mortality were $9.1 \%$ and $6.8 \%$ respectively. At last follow-up, all patients had few or no symptoms (NYHA class 1or 2). Eighteen patients (66.7\%) had TR grade $0-1$, five patients (18.5\%) had TR grade 2 and four patients (14.8\%) had TR grade 3 but remained asymptomatic under medical treatment. No patient was reoperated. On echocardiography, there was a significant reduction in the size of the right ventricle

Department of Cardiac Surgery, 1st November Hospital, Oran 31000, Algéria and tricuspid annulus with a mean tricuspid gradient of $3 \mathrm{~mm} \mathrm{Hg}$ at the last follow-up.

\section{Discussion/Conclusion}

Tricuspid annuloplasty with a PTFE linear strip is effective for the treatment of functional tricuspid regurgitation with good midterm results. This technique is a good alternative of annuloplasty in case of unavailability of a prosthetic ring especially in developing countries. A long-term follow up is needed to see if these results are sustainable.

Published: 16 December 2015

doi:10.1186/1749-8090-10-S1-A189

Cite this article as: Chibane et al:: Midterm results of tricuspid annuloplasty with a homemade PTFE flexible ring. Journal of Cardiothoracic Surgery 2015 10(Suppl 1):A189.
Submit your next manuscript to BioMed Central and take full advantage of:

- Convenient online submission

- Thorough peer review

- No space constraints or color figure charges

- Immediate publication on acceptance

- Inclusion in PubMed, CAS, Scopus and Google Scholar

- Research which is freely available for redistribution
() Biomed Central 